\title{
Advanced Infusion Techniques with 3-D Printed Tooling
}

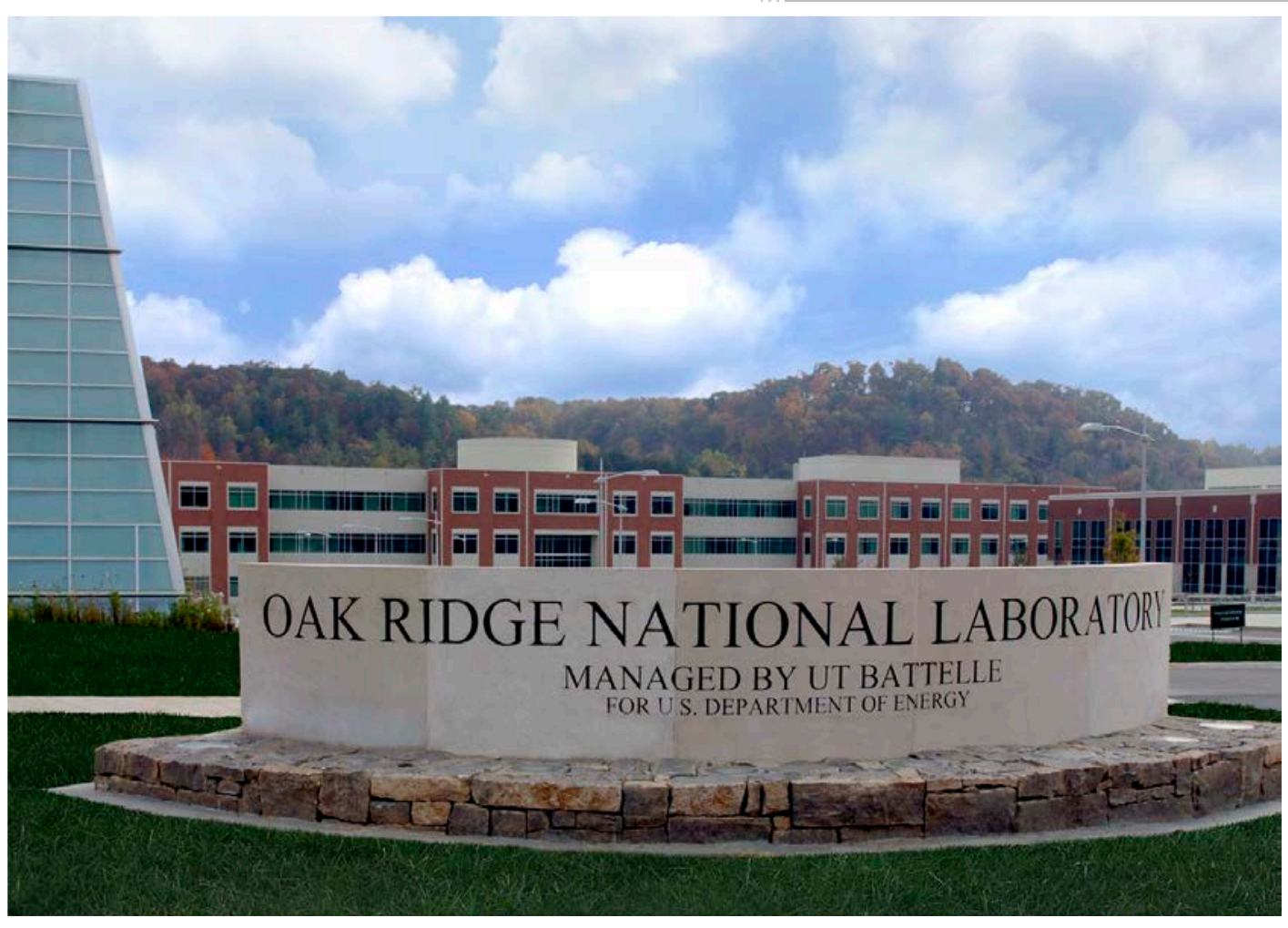

CRADA FINAL REPORT NFE-15-05575

Approved for Public Release. Distribution is Unlimited.
David Nuttall Amy Elliott Brian Post Lonnie Love

May 10, 2016 


\section{DOCUMENT AVAILABILITY}

Reports produced after January 1, 1996, are generally available free via US Department of Energy (DOE) SciTech Connect.

Website http://www.osti.gov/scitech/

Reports produced before January 1, 1996, may be purchased by members of the public from the following source:

National Technical Information Service

5285 Port Royal Road

Springfield, VA 22161

Telephone 703-605-6000 (1-800-553-6847)

TDD 703-487-4639

Fax 703-605-6900

E-mail info@ntis.gov

Website http://www.ntis.gov/help/ordermethods.aspx

Reports are available to DOE employees, DOE contractors, Energy Technology Data Exchange representatives, and International Nuclear Information System representatives from the following source:

Office of Scientific and Technical Information

PO Box 62

Oak Ridge, TN 37831

Telephone 865-576-8401

Fax 865-576-5728

E-mail reports@osti.gov

Website http://www.osti.gov/contact.html

This report was prepared as an account of work sponsored by an agency of the United States Government. Neither the United States Government nor any agency thereof, nor any of their employees, makes any warranty, express or implied, or assumes any legal liability or responsibility for the accuracy, completeness, or usefulness of any information, apparatus, product, or process disclosed, or represents that its use would not infringe privately owned rights. Reference herein to any specific commercial product, process, or service by trade name, trademark, manufacturer, or otherwise, does not necessarily constitute or imply its endorsement, recommendation, or favoring by the United States Government or any agency thereof. The views and opinions of authors expressed herein do not necessarily state or reflect those of the United States Government or any agency thereof. 
ORNL/TM-2016/192

CRADA/NFE-15-05575

Energy \& Transportation Science Division

Advanced Manufacturing Office

\title{
ADVANCED INFUSION TECHNIQUES WITH 3-D PRINTED TOOLING
}

\author{
David Nuttall, ORNL \\ Amy Elliott, ORNL \\ Brian Post, ORNL \\ Lonnie Love, ORNL
}

Date Published: May 10, 2016

\author{
Prepared by \\ OAK RIDGE NATIONAL LABORATORY \\ Oak Ridge, Tennessee 37831-6283 \\ Managed by \\ UT-BATTELLE, LLC \\ for the \\ US DEPARTMENT OF ENERGY \\ Under contract DE-AC05-00OR22725
}

Approved for Public Release 


\section{CONTENTS}

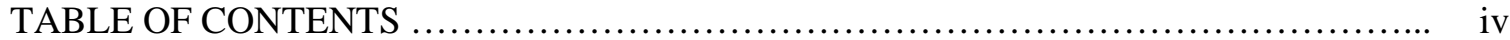

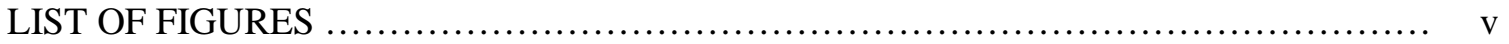

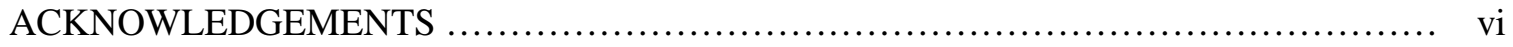

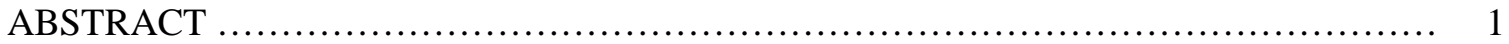

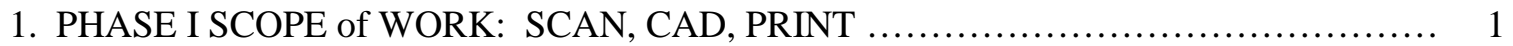

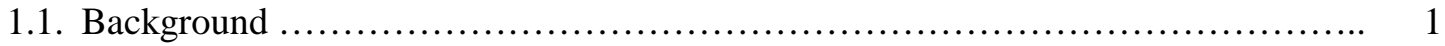

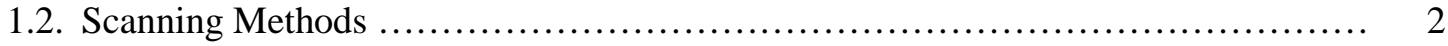

1.2.1. In-House Hand Scanning with Sense Hand Held 3D Scanner ................. 2

1.2.2. Professional Scanner Creaform Go!SCAN 3D ............................... 3

1.2.3. In-House FARO Laser Tracker ........................................ 4

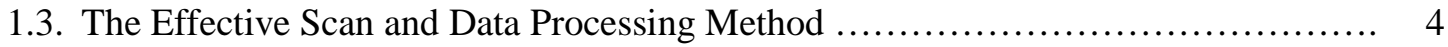

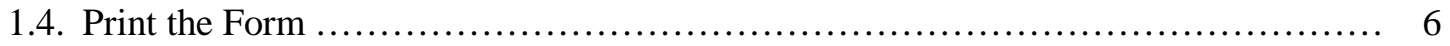

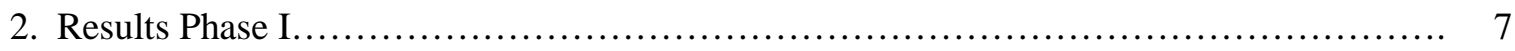

3. Partner Background ............................................................... 8

Appendix A:

Anticipating a Phase II, the following Scope of Work summarizes the intended efforts

References ........................................................................... 10 


\section{LIST OF FIGURES \& TABLES}

FIGURE DESCRIPTION

PAGE

$1 \quad$ Canoe Plug as received from MVP, in preparation for Hand Scanning 2

2

3

Canoe Key Definitions

2

Hull Lines

Sense Hand Held 3D Scanner

2

Resulting Bow Scan, Incomplete Data Fill

3

Go!SCAN50

Immense Detail, with tessellation structures in the shaded areas

3

5

6

7

8

FARO Laser Tracker

3

3

Laser Tracker in use, tracing of the hull contour

Splines and Lofts

4

9

10

Completed CAD model

5

Half-shell showing structural support

Full CAD mold assembly

Image of BAAM Print Plan

BAAM Print underway

Print complete

Bow perspective of plug fit test

Stern perspective of plug fit

18

TABLE

DESCRIPTION

PAGE

Comparison of Scanners 


\section{ACKNOWLEDGEMENTS}

This CRADA NFE-15-05575 was conducted as a Technical Collaboration project within the Oak Ridge National Laboratory (ORNL) Manufacturing Demonstration Facility (MDF) sponsored by the US Department of Energy Advanced Manufacturing Office (CPS Agreement Number 24761). Opportunities for MDF technical collaborations are listed in the announcement "Manufacturing Demonstration Facility Technology Collaborations for US Manufacturers in Advanced Manufacturing and Materials Technologies” posted at http://web.ornl.gov/sci/manufacturing/docs/FBO-ORNL-MDF-2013-2.pdf. The goal of technical collaborations is to engage industry partners to participate in short-term, collaborative projects within the Manufacturing Demonstration Facility (MDF) to assess applicability and of new energy efficient manufacturing technologies. Research sponsored by the U.S. Department of Energy, Office of Energy Efficiency and Renewable Energy, Advanced Manufacturing Office, under contract DE-AC05-00OR22725 with UT-Battelle, LLC. 


\section{ABSTRACT}

The manufacturing of tooling for large, contoured surfaces for fiber-layup applications requires significant effort to understand the geometry and then to subtractively manufacture the tool. Traditional methods for the auto industry use clay that is hand sculpted. In the marine pleasure craft industry, the exterior of the model is formed from a foam lay-up that is either hand cut or machined to create smooth lines. Engineers and researchers at Oak Ridge National Laboratory's Manufacturing Demonstration Facility (ORNL MDF) collaborated with Magnum Venus Products (MVP) in the development of a process for reproducing legacy whitewater adventure craft via digital scanning and large scale 3-D printed layup molds. The process entailed 3D scanning a legacy canoe form, converting that form to a CAD model, additively manufacturing (3-D Print) the mold tool, and subtractively finishing the mold's transfer surfaces.

Future work will include applying a gelcoat to the mold transfer surface and infusing using vacuum assisted resin transfer molding, or VARTM principles, to create a watertight vessel. The outlined steps were performed on a specific canoe geometry found by MVP's principal participant. The intent of utilizing this geometry is to develop an energy efficient and marketable process for replicating complex shapes, specifically focusing on this particular watercraft, and provide a finished product for demonstration to the composites industry. The culminating part produced through this agreement has been slated for public presentation and potential demonstration at the 2016 CAMX (Composites and Advanced Materials eXpo) exposition in Anaheim, CA.

Phase I of this collaborative research and development agreement (MDF-15-68) was conducted under CRADA NFE-15-05575 and was initiated on May 7, 2015, with an introduction to the MVP product line, and concluded in March of 2016 with the printing of and processing of a canoe mold. The project partner Magnum Venous Products (MVP) is a small business. Phase II as discussed herein is under consideration by MVP as of this writing. Overall, it is anticipated that developing this process for manufacturing tooling for complex contoured surfaces has applicability to naval and other watercraft as well as bathrooms and large trucks.

\subsection{PHASE I SCOPE of WORK: SCAN, CAD, PRINT}

\section{$1.1 \quad$ BACKGROUND}

Additive manufacturing / 3-D Printing / Fused Deposition Manufacturing (FDM) is a technique in which material is extruded, following a pattern controlled by an $\mathrm{x}-\mathrm{y}$ gantry, onto a z-height control bed. Material is delivered to the gantry mounted extruder in pellet form, where it then is heated and processed through a compaction screw to be extruded at rates between 70 and 100 pounds per hour. ORNL has optimized the process controlling shapes to a tolerance of \pm 0.050 ” using a 0.2 inch nozzle with acrylonitrile butadiene styrene (ABS) (80\%) / carbon fiber fill (20\%). This technique has proven to produce smooth lines as seen in the 3-D printed Shelby Cobra $(2014)^{2}$, the printed utility vehicle (PUV) (2015), and the Willys Jeep body (2015).

MVP is the leading manufacturer of a variety of equipment targeting composites applications. They serve customers in boat, bus, rail, truck, bathroom, bathtub, pipe, and other industrial or production applications. ${ }^{1}$ The idea originated for this CRADA out of a simple walk in the pastures around the family farm. Peter Hedger, Jr. - a third generation leader within the family business, came across the plug (figure 1) for what is heralded as a prime whitewater canoe based on the Ocoee design. This design is built with the perfect 'rocker' positioned aft of center to allow the solo paddler maximum control in a canoe designed to handle streams and rivers with moderate rapids. While touring Oak Ridge National 
Laboratory's Manufacturing Demonstration Facility, Peter observed what was happening in automotive applications with additive manufacturing, and felt transfer of this technology to a boat or canoe mold was extremely plausible.

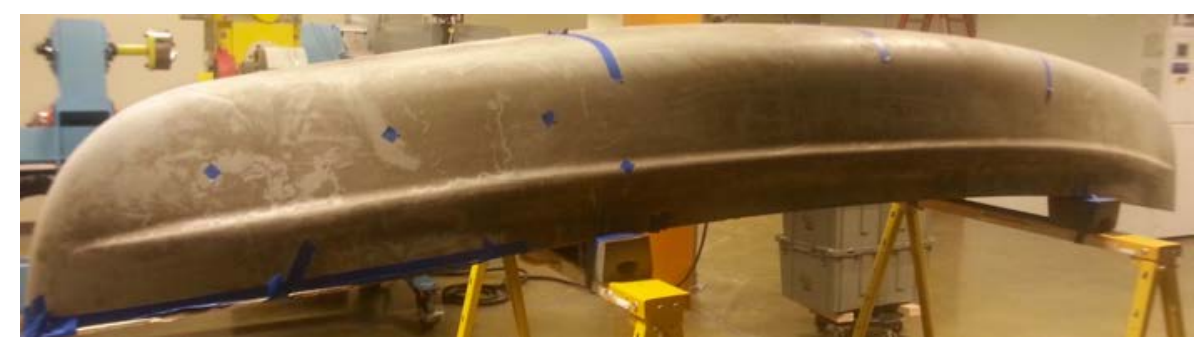

Figure 1 Canoe plug as received from MVP, in preparation for hand scanning.

Considering energy efficiency and time required to rejuvenate this particular canoe design, the plan was set to capture a digital scan of the plug, and go directly to the mold form through additive manufacturing. This eliminated the time and energy costs of traditional pre-build methodology: (re)construction of the plug, fiberglass layup, and structural reinforcement. These steps typically take weeks to create a tool of this size.

\subsection{SCANNING METHODS}

The approach for scanning the canoe silhouette was to physically measure the length, breadth, height, and capture details such as depth of gunnel, to determine overall cube space. This allowed identification of the general location of the rocker, location of max breadth, and overall height. The canoe form's cube space was 134 ” x 29.25” x 24”.

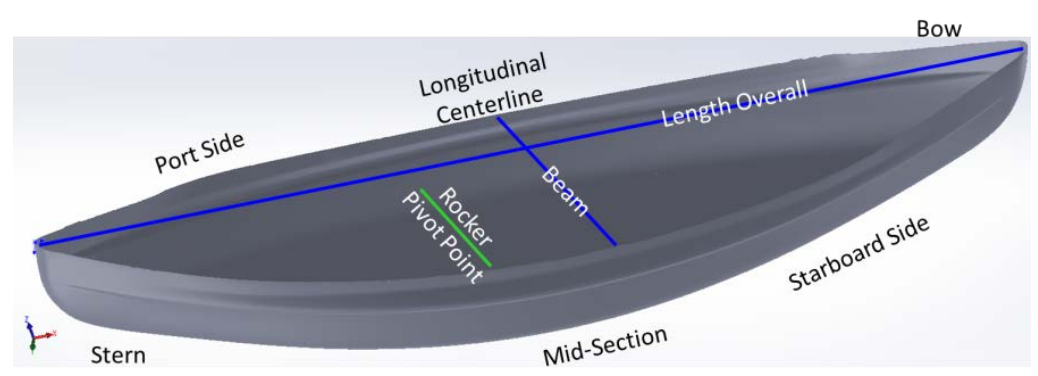

Figure 2 Canoe key definitions.

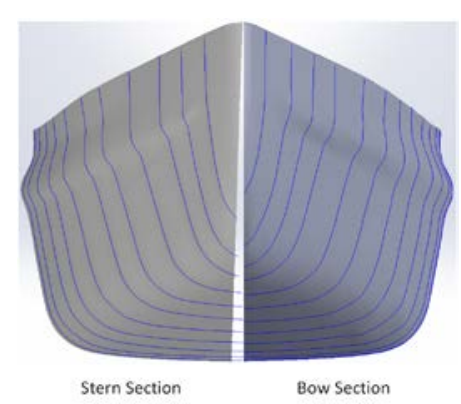

Figure 3 Hull lines.

To initiate a printed design, one begins with a computer aided design (CAD) model in stereo lithography (.stl) format, which may originate from a drawing, or a scan with data processing via any number of software packages. This project incorporated a scan. The canoe plug provided by MVP was inverted shell up and scanned using three various types of scanners: a handheld scanner for moderate sized projects, a contracted scan company, and a commercially available laser tracking system. Of the three options, the results found with the third option were the most successful at capturing the contour of the plug and transposing to a useable CAD dataset.

\subsubsection{In-House Hand Scanning with Sense Hand Held 3D Scanner}

The Sense Handheld 3D Scanner (figure 4) was chosen as a low cost option to determine the feasibility and quality of the scan. The advertised specifications for very detailed objects were promising, and therefore the Sense was acquired and tested. 
A major discovery in using the Sense Scanner was the limitation in capturing the entire form. Although published information ${ }^{3}$ indicates a resolution of $0.9 \mathrm{~mm}$ at $0.5 \mathrm{~m}$, the Sense was unable to follow the smoothness of the canoe forms curves, leading to incomplete data fill and the inability to start a scan in the midsection of the plug. The initial plans were to scan the plug in three sections: bow, mid-section, and stern, and then 'stitch' the information together. This proved unsuccessful due to the smoothness of the surface - there were no features for the scan to recognize as it progressed across the surface, limited data (e.g. incomplete fill), and the limited ability to process the output data using the proprietary software with the Sense 3D scanner (figure 5).

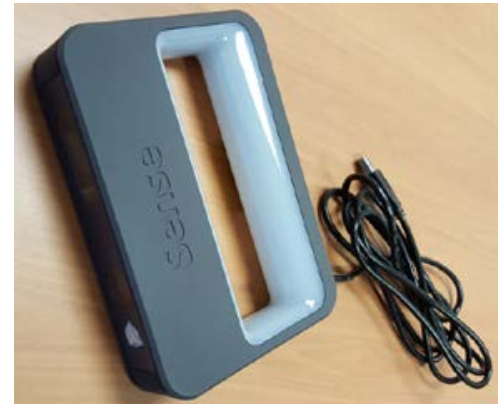

Figure 4 Sense Hand Held 3D Scanner.

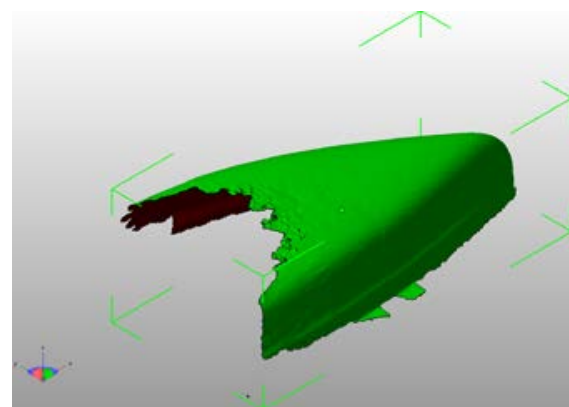

Figure 5 Resulting bow scan, incomplete data fill.

\subsubsection{Professional Scanning with Creaform Go!SCAN 3D, contracting Visionary Fabrication \& 3D Design LLC}

The second scanning attempt was with a contracted company, Visionary Fabrication \& 3D Design LLC, who supplied services for scanning the canoe plug with a Creaform Go!SCAN 50 unit (figure 6). The accuracy of this unit is published ${ }^{4}$ as $0.5 \mathrm{~mm}$ at $0.4 \mathrm{~m}$. Specialized treatment of the surface was required basically placing stickers on the surface in a random pattern allowing the vision pick-up to recognize various features. Extraordinary results in detail were obtained, however the dataset was unreasonable in volume even after multiple attempts employing software specialized for .STL refinement, Geomagic Studio. Typical 3D printers follow CAD instructions in 2D, layer by layer, which are in reality linear specifically a printer head will follow directions to travel in straight lines. For a curve, the line segments are broken into tangent lines, so when considering 3D, the surface is in the form of triangles. As seen in figure 7, the tessellations, or triangular shapes that the CAD program combines to define the surface or feature, are extremely dense and thus would cause the 3D printer to attempt to print multiple straight line segments the length of the legs of the triangles, and would not leave the actual features of smooth curves.

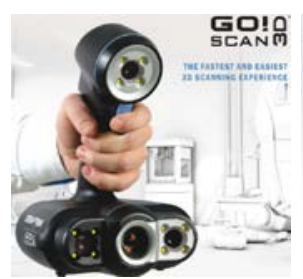

Figure 6 GO!SCAN50.

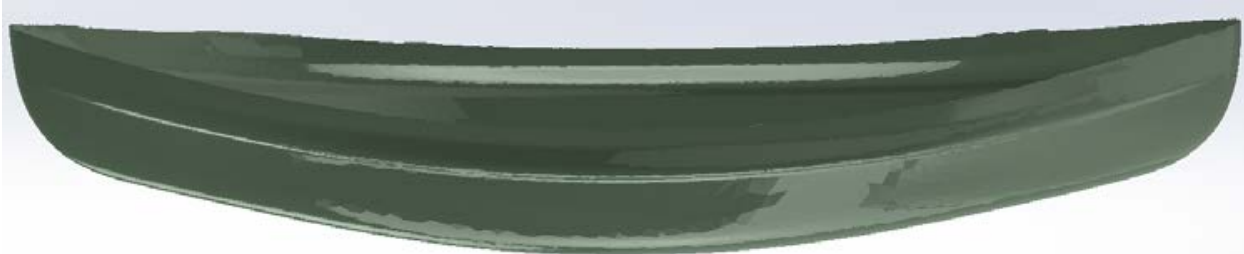

Figure 7 Immense detail with tessellation structures in the shaded areas.

A common issue with both the 3D Hand Held scanner and the data set received from Visionary Fabrication \& 3D Design $L L C$ was that each data set was in the form of a surface scan without material depth, and therefore did not create a three dimensional model. Thus Solidworks software was then unable to use the data to invert to an external solid surface that mirrored the surface scan. 


\subsubsection{FARO Laser Tracker Spline Line Scanning}

It was not anticipated that, even though 3D scanning is simple to implement, the file sizes would be prohibitive for actual use in digital manufacturing. After investigating other options, the FARO Laser Tracker system located at the MDF seemed to be a viable solution, leading to discussions with the equipment's principle investigator. The potential for success in obtaining a useable dataset that would be manageable in size was promising. The FARO Laser Tracker method proved to be optimal, noting that the accuracy of this unit per the manufacturer's information ${ }^{5}$ is $0.011 \mathrm{~mm}$ at $20 \mathrm{~m}$.

The technique used for the FARO Laser Tracker was to energize the unit, acquire the laser path with the mirrored spherical probe, and trace the surface of the canoe creating a series of data points. This information was then exported to a CAD program where it was able to be refined into the desired surface.

In comparison with the other two methods discussed earlier in this report, the FARO Laser Scanner took more setup, however the trade-off was that probing the surface contours resulted in a much more manageable dataset. The techniques used and the results of the FARO scanning are discussed in the next section.

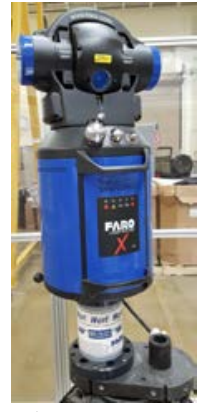

Figure 8 FARO laser tracker.

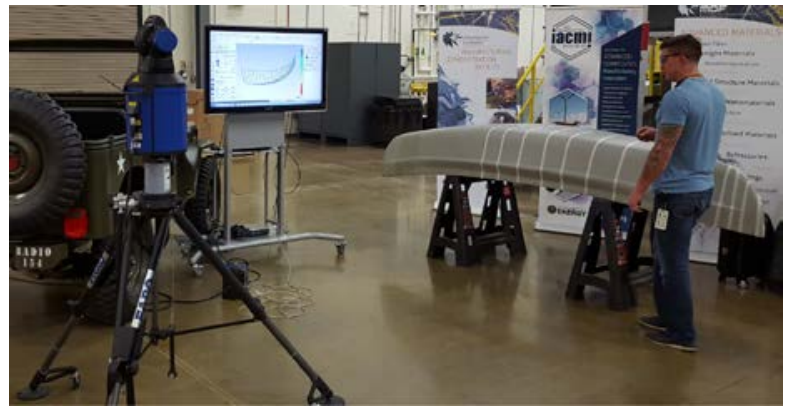

Figure 9 Laser tracker in use, tracing of the hull contour.

\subsection{THE EFFECTIVE SCAN AND DATA PROCESSING METHOD}

As mentioned with the Sense Handheld 3D Scanner and the Creaform Go!SCAN 3D the resulting scans of the existing canoe plug produced a data set that was either incomplete or overwhelming in size. Thus, surface probing with the FARO arm was enlisted to measure the contours along the length of the watercraft. Since the physics of plowing through, or in a canoe's case, over the water requires symmetry port to starboard, the approach was to trace the keel, the gunnel, and then model the port side from bow to stern. Spline lines approximately every 6 inches in highly detailed areas (e.g. bow and stern), and 12 inches through the midsection, connecting keel to gunnel, were traced and recorded. The captured data was then imported into CAD software (SolidWorks 2015) and the splines were merged progressively with the 'Add Loft Section' tool to form half of the shell. To complete the CAD form, the image was mirrored creating a complete shell representing the future structure. Figure 10 is a screen capture of an intermediate step illustrating splines to lofted panels, and figure 11 illustrates the finished CAD canoe. 


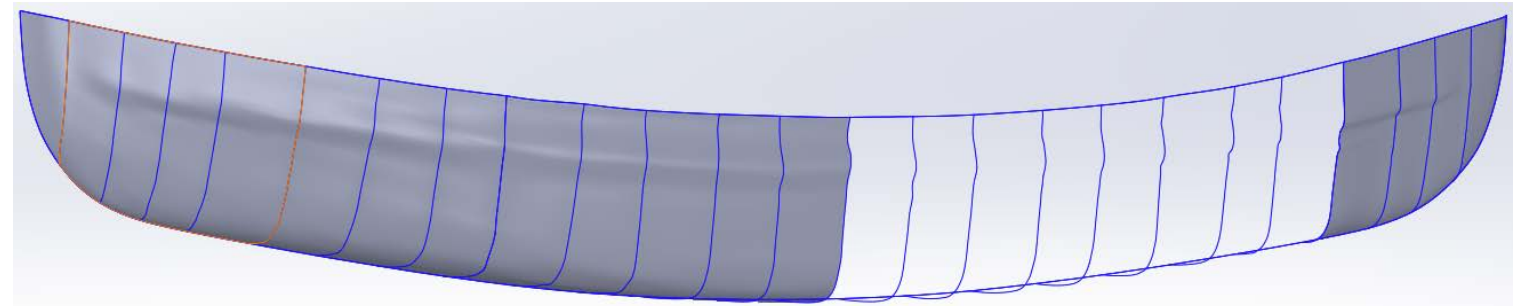

Figure 10 Splines and lofts.

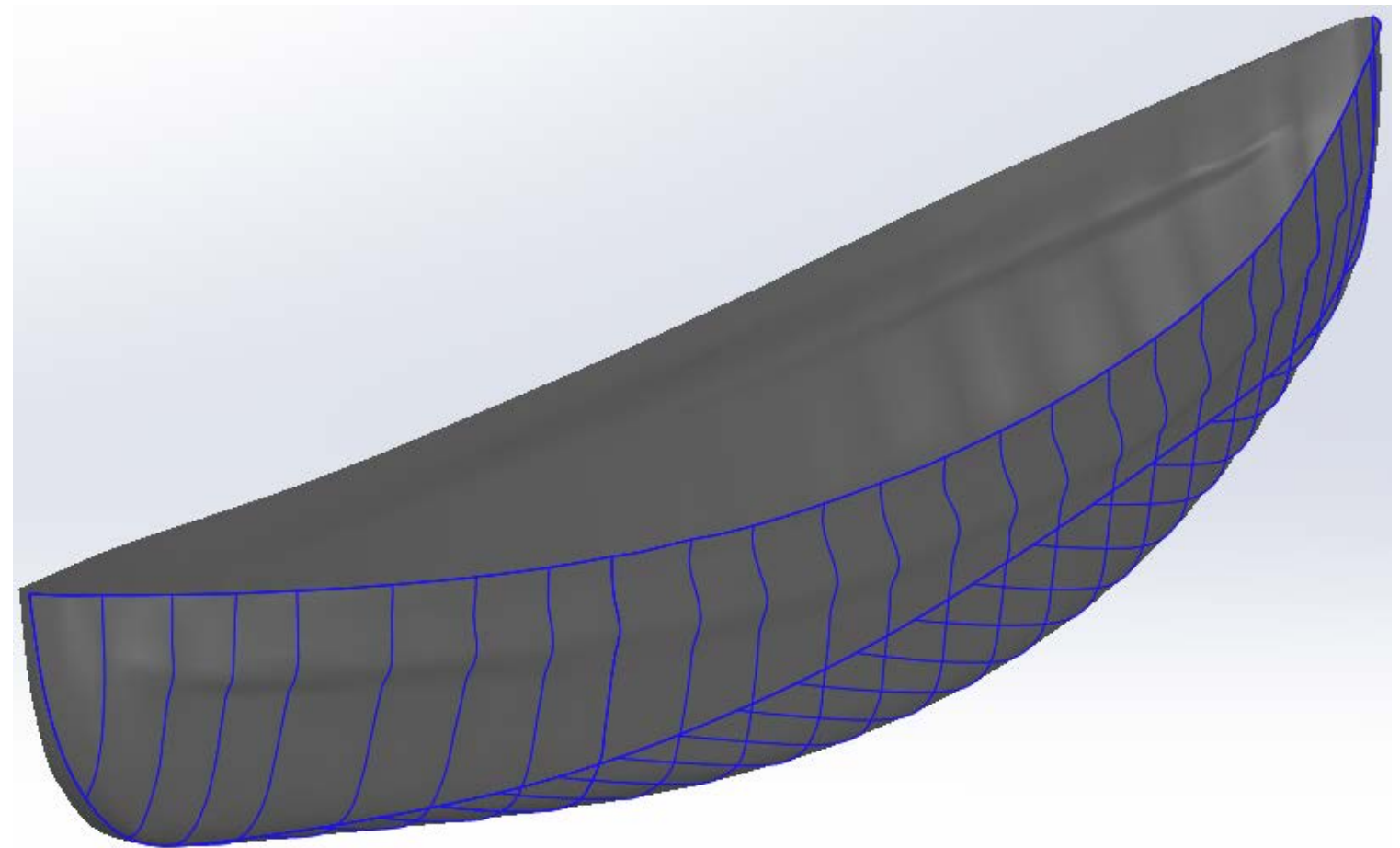

Figure 11 Completed CAD model.

The results of importing the contours and incorporating them into a lofted geometry in Solidworks were ideal. The contours were mathematically smooth and provided closure on the entire surface in symmetry. After obtaining a high-fidelity 3D model of the canoe, the next steps involved converting into the mold geometry. To accomplish this, the data set was transformed again - essentially turning it inside-out. Structural support elements were added to establish the resulting shape that would become the printed mold (figures 12 \& 13).

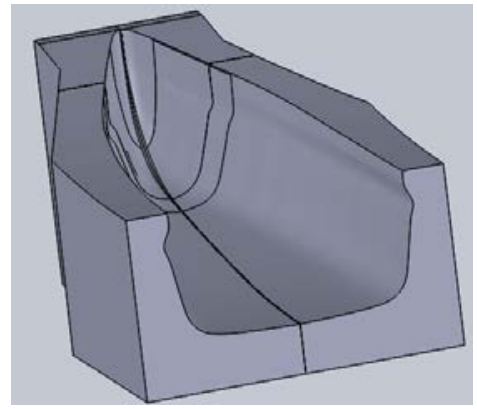

Figure 12 Half-shell showing support structure.

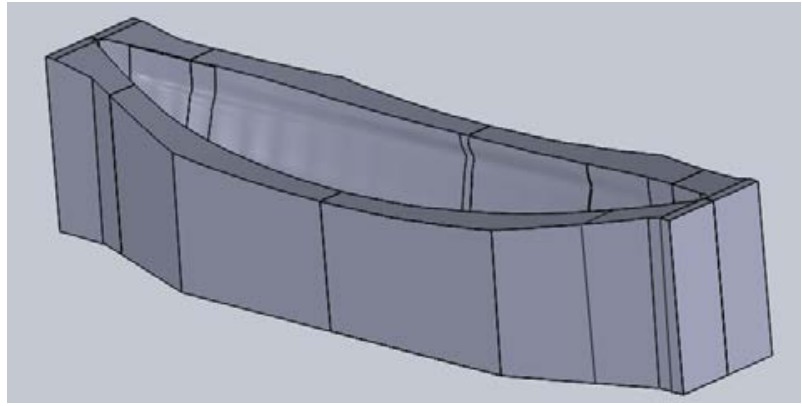

Figure 13 Full CAD mold assembly. 
The success of numerous printing projects incorporating the Cincinnati BAAM system has indicated building in the $\mathrm{z}$ direction provided the greatest detail control. Considering that the rocker and gunnel are the unique features of this version of the Ocoee canoe, this was the intentional build direction. With a vertical print limitation of six feet, a plan to section the canoes' overall length was prerequisite. Thus, four sections: bow port, bow starboard, stern port, and stern starboard were sectioned in the CAD data for the final 3D print form. With the CAD complete, the saved .stl file was imported into ORNL's slicing software, where the represented structure reduced to 2D planner data in approximately one-thousand fourhundred layers (figure 14).

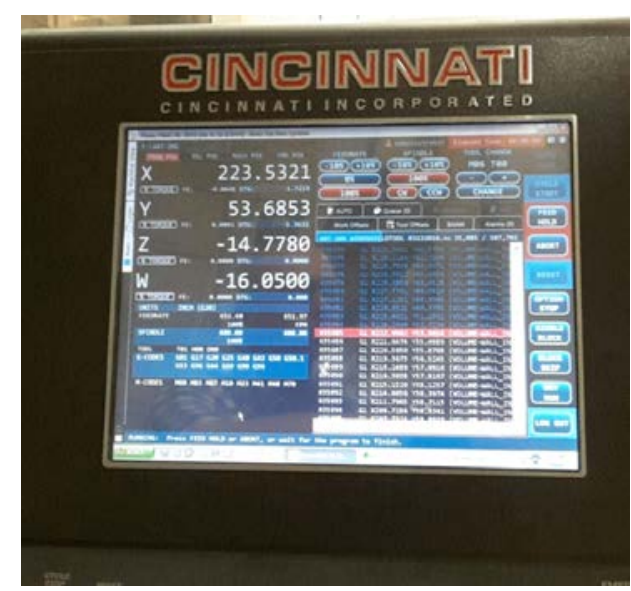

Figure 14 Image of BAAM print plan.

The sliced data was transferred to the BAAM and the print was started. The four pillars began to take shape, and approximately 17 hours and 1350 pounds of material later, the mold forms were complete (figures 15 and 16). After cooling for an additional six hours, the forms were removed, aligned, and a sample fit took place (figures 16 and 17) confirming the net shape of the printed mold.

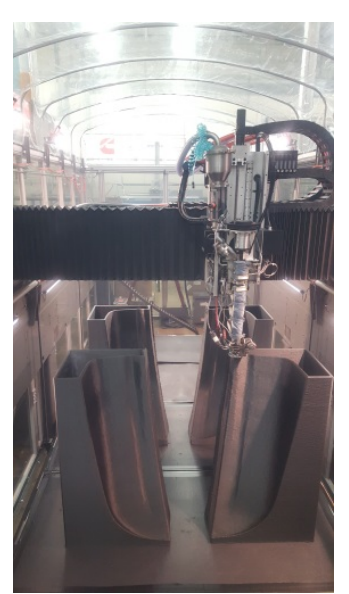

Figure 15 BAAM print underway.

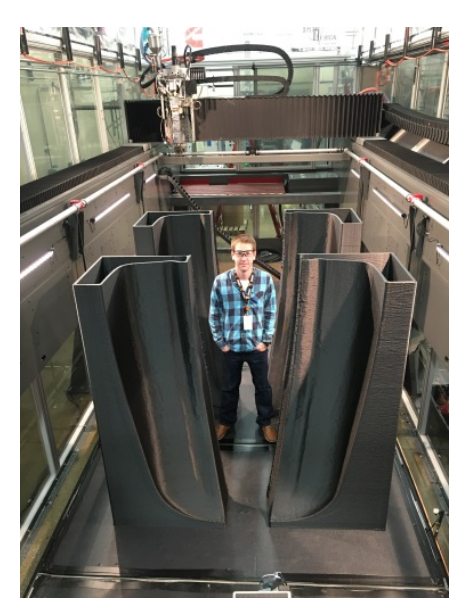

Figure 16 Print complete. 


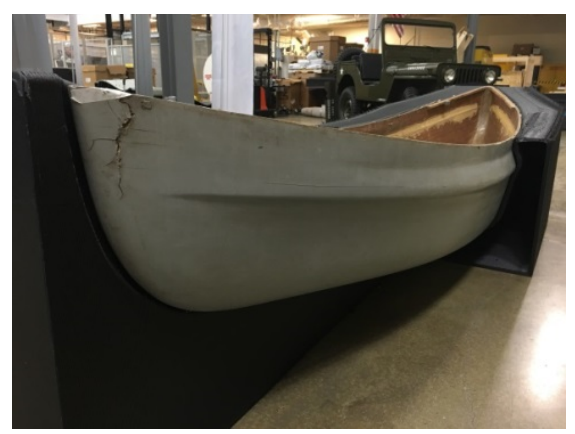

Figure 17 Bow perspective of plug fit test.

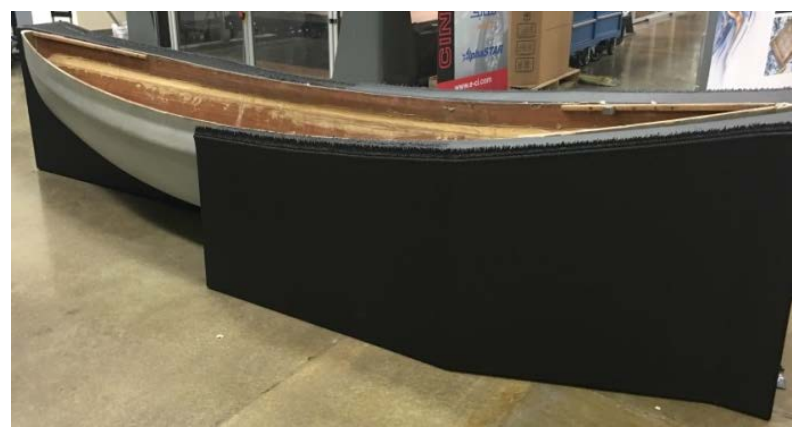

Figure 18 stern perspective of plug fit.

A wrap-up meeting was held with MVP and TruDesign to determine next steps in preparation for the CAMX Conference scheduled for September 2016 in Anaheim, CA. Based on the initial quality of the print, it has been decided to surface finish the current mold group and show the molds as a proof of concept at the conference. Additionally, with the completion of the printing of the mold, the timing for the CRADA was at end and led to the proposal for a Phase II CRADA, which is underway at the time of this writing, to complete a new mold that will accommodate a silicon bag and be ready for the infusion process at the CAMX Conference. The general outline for the second phase is found in Appendix A.

\subsection{Results PHASE I:}

The major take-aways from this CRADA effort are many. Specifically, there was a notable usability difference between the scanning systems, and the output data files as received, were limited relative to SolidWorks CAD software. The Sense Handheld 3D Scanner and the Creaform Go!SCAN 3D were a factor of 100 different in outright affordability, however the end result was common - an unusable data format. See table 1 for comparison of all scanners. Secondly, the success of the transition from the FARO Laser Scanner data to a usable sliced dataset, although requiring several additional processing steps through CAD, was encouraging and has set precedence for the method for shape transference here at the MDF. Finally, the condition of the mold as compared to net-shape was extremely encouraging.

\subsection{Partner Background}

MVP has been providing pumping systems and other products that have been used by companies who manufacture products such as hot tubs, boats, wind turbine blades, automotive parts, radar domes and more for over 60 years. The product line includes the Patriot ${ }^{\mathrm{TM}}$, UltraMAX ${ }^{\mathrm{TM}}$ and Pro Series pumping systems, Versa-Wind line of standard and multi-axis filament winders, Flex Molding Process for closed molding, and multiple systems designed for the dispense of specialty materials. MVP has broadened its product line to include equipment and applications for the foam and polyurethane industries, along with polyureas, adhesives and epoxies, MVP is pushing to showcase quality and expertise to many industries. MVP is the largest composites equipment manufacturer in the world. 
TABLE 1: COMPARISON OF SCANNERS

\begin{tabular}{|c|c|c|c|c|c|}
\hline Scanner & Medium & Resolution & Price Point & Pros & Cons \\
\hline $\begin{array}{l}\text { Sense Handheld } \\
\text { 3D Scanner }\end{array}$ & $\begin{array}{l}\text { White Light mono- } \\
\text { pickup }\end{array}$ & $\begin{array}{l}0.9 \mathrm{~mm} \\
\text { @ } 0.5 \mathrm{~m}\end{array}$ & $\$ 400$ & $\begin{array}{l}\text { Lightweight, } \\
\text { Portable with } \\
\text { laptop }\end{array}$ & $\begin{array}{l}\text { Level of detail limited } \\
\text { by monocular pick-up; } \\
\text { Requires detailed } \\
\text { contour for successful } \\
\text { data acquisition }\end{array}$ \\
\hline $\begin{array}{l}\text { Creaform } \\
\text { Go!SCAN50 }\end{array}$ & $\begin{array}{l}\text { White Light Stereo- } \\
\text { pickup }\end{array}$ & $\begin{array}{l}0.5 \mathrm{~mm} \\
\text { @ } 0.4 \mathrm{~m}\end{array}$ & $\$ 40,000$ & $\begin{array}{l}\text { Lightweight, } \\
\text { Portable w/ } \\
\text { laptop }\end{array}$ & $\begin{array}{c}\text { Hyper data collection } \\
\text { overwhelms the CAD } \\
\text { system; } \\
\text { Requires treating / } \\
\text { marking of the entire } \\
\text { surface contour for } \\
\text { successful data } \\
\text { acquisition }\end{array}$ \\
\hline $\begin{array}{l}\text { FARO Laser } \\
\text { Tracker } X\end{array}$ & $\begin{array}{l}\text { Red Laser Class } 1 \text {, } \\
\text { line of sight return }\end{array}$ & $\begin{array}{l}0.011 \mathrm{~mm} \\
@ 20 \mathrm{~m}\end{array}$ & $\$ 37,000$ & $\begin{array}{l}\text { Systematic; } \\
\text { Controlled to the } \\
\text { data set desired }\end{array}$ & $\begin{array}{l}\text { Post processing more } \\
\text { in-depth for the results } \\
\text { desired }\end{array}$ \\
\hline
\end{tabular}


Appendix A: Anticipating a PHASE II, the following Scope of Work summarizes the intended efforts

\section{PHASE II SCOPE of WORK:}

1. Mold Preparation

1.1. Define Design Parameters

Flange requirements for infusion, structural material for connecting mold sections, etc.

1.2. Data Conversion Requirements

Determine adequacy of print from Phase I - stereo lithography print-thru, etc.

1.3. Transition to Machine Language

Preferred Slicing direction, location of overlap, etc.

1.4. $\quad$ Printing \& Finishing

Schedule the print, monitor, and remove

Transition to 5-Axis mill, Surface Prep, Surface, Final mill

Prepare a silicone bag for repeat assembly \& infusion of the molds

2. Mold Infusion Preparation

2.1. $\quad$ Planning Material Schedule

Determine finished product final weight allowable, stress loads \& structural requirements, etc.

2.2. Material Kitting

Prepare woven \& core materials

2.3. Lay-up Methods

Schedule \& prepare the mold for infusion, physically installing the material lay-up

2.4. Bagging Preparation

Bag the mold with pre-formed silicone bag

3. Infusing \& Part Retrieval

3.1. Equipment Connection

Equipment layout, location for infusion vs vacuum port position for optimum fluid flow

3.2. Chemistry Preparation

Discussion regarding resin chemistries: thermoset vs thermoplastic vs other

3.3. Infusion

Physically performing the infusion, record events

3.4. Part Retrieval

Physically remove the part, record events

4. Results

4.1. Cost Comparison of Advanced v Traditional Methodologies

Consult with MVP regarding content 


\section{References:}

[1] "History - Magnum Venus Products," Magnum Venus Products History Comments. [Online]. Available at: http://www.mvpind.com/us/history/. [Accessed: 03-May-2016].

[2] Curran, S., Chambon, P., Lind, R., Love, L. et al., "Big Area Additive Manufacturing and Hardwarein-the-Loop for Rapid Vehicle Powertrain Prototyping: A Case Study on the Development of a 3-DPrinted Shelby Cobra," SAE Technical Paper 2016-01-0328, 2016, doi:10.4271/2016-01-0328.

[3] “Sense ${ }^{\mathrm{TM}} 3 \mathrm{D}$ scanner," Sense 3D Scanner. [Online]. Available at:

http://www.3dsystems.com/shop/sense/techspecs. [Accessed: 03-May-2016].

[4] “Technical Specifications: Go!SCAN 3D,” 3D Laser Scanner, Coordinate Measuring Machine and 3D Scanning. [Online]. Available at: http://www.creaform3d.com/en/technicalspecifications-goscan-3d. [Accessed: 03-May-2016].

[5] “04REF201-134-EN - FARO Laser Tracker X Tech Sheet.pdf”. [Online]. Available at: http://www.trosol.com/laser_tracker/downloads/04REF201-134-EN\%20\%20FARO\%20Laser\%20Tracker\%20X\%20Tech\%20Sheet.pdf. [Accessed: 03-May-2016]. 